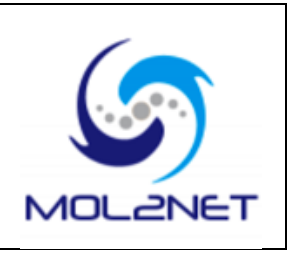

\title{
Synthesis and Characterization of Carbon Nanotube/Hydroxyapatite/Clay Based Hybrid Antimicrobial Biomaterial for Potential Tissue Engineering Application
}

\author{
Subrata Kar ${ }^{1,2}$, Papiya Nandy ${ }^{2}$, Ruma Basu ${ }^{2,3}$ and Sukhen Das $1,2,4, *$ \\ ${ }^{1}$ Physics Department, Jadavpur University, Kolkata-700 032, India. \\ ${ }^{2}$ Centre for Interdisciplinary Research and Education, Kolkata 700 068, India \\ ${ }^{3}$ Physics Department, Jogamaya Devi College, Kolkata 700026 \\ ${ }^{4}$ Indian Institute of Engineering, Science and Technology, Howrah, India \\ * Author to whom correspondence should be addressed
}

\section{Published: 4 December 2015}

\begin{abstract}
Inorganic ceramic materials have recently been enjoying a great deal of attention for uses as biomaterial over the traditionally used polymeric material. The ability of silica based ceramics to release $\mathrm{Si}$-containing ionic products makes them osteoconductive and their special surface composition has drawn considerable attention for its use as osteogenic proliferation, differentiation and gene expression of tissue cells. Here Pristine Multiwalled carbon nanotube (MWCNT) was functionalized by acid oxidation and used as template for nucleation of hydroxyapatite crystal. The CNT-HAP thus formed was further reinforced with exfoliated Montmoriollite(MMT) clay to increase the mechanical property of the nanocomposite. The synthesized composite viz CNT-HAP (HC) and CNT(HAP)-MMT(CHC) were characterized by fourier transform infrared spectroscopy(FTIR), X-ray diffraction(XRD), Scanning electron microscopy and transmission electron microscopy(TEM) and thermogravimetric analysis(TGA) . The biomedical application of CHC, blood compatibility was studied in terms of hemolysis assay and platelet adhesion assay. Finally, in vitro dissolution assay and the antibacterial activity of the material were further explored for establishing its use as an antibacterial biomaterial. The nanocomposite thus designed exhibited a promising candidate as an antimicrobial biomaterial for tissue Engineering application..
\end{abstract}


Keywords: Clay; Carbon nanotube; Hydroxyapatite; Nanocomposites; Hemocompatibility; Biomineralization; Antimicrobial biomaterial

\section{Introduction}

Clays and clay minerals are widely utilized in our society are in geology, agriculture, construction, environmental applications and in Traditional applications that include ceramics, paper, paint, plastics, chemical carriers, decolorization, and catalysis etc(1). Biomedical application of clay dates back to prehistoric era where clay served in wounds and skin irritations caused by Homo erectus and $H$. neanderthalensis. Clays were ingested to treat stomach and intestinal problems. Clay application finds its application as active ingredients in antacids, antidiarrhoerics, tropical applications such as cosmetic creams, powders and in pharmaceutics as excipients(2). Precisely the rich electrochemistry of clay mineral attributes to its uses in human health and disease. Montmorillonite is a layered aluminosilicate, belongs to smectite group of clay which consists of a one edge shared octahedral sheet of aluminum hydroxide fused in between two silica tetrahedral(3). The susceptibility of the charged smectite particles for swelling and delamination, results in rich selection of potential interactions between organic molecules and the clay particles. Inorganic ceramic materials have been enjoying a great deal of attention for uses as biomaterials over the traditionally used polymeric material. In the late 1960's Ceramics material replaced the earlier used metals for implants(2). Clay particles have also been implemented in dental adhesives for improving bond strength. MMT particles have also been used as scaffold in bone therapies. The ability of silica based ceramics to release Sicontaining ionic products makes them osteoconductive and their special surface composition has drawn considerable attention for its use as osteogenic proliferation, differentiation and gene expression of tissue cells(4). Hydroxyapatite (HAp, $\left.\mathrm{Ca}_{10}\left(\mathrm{PO}_{4}\right)_{6}(\mathrm{OH})_{2}\right)$ ceramics has served as an excellent biomaterial due to their close chemical composition with the bone and in biomedical field as drug delivery vehicle. The ability of HAP to form chemical bond with host tissues offers a great advantage over allografts and metal implants. The poor mechanical property has lead to the discovery of HAP based composites with improved mechanical properties(5).

Carbon nanotube (CNT) is an allotrope of carbon received a significant curiosity pertaining to its excellent physical, chemical and mechanical properties(6). However there has been commendable use of CNT in biology and medicine in terms of pharmacy, medicine, drug delivery vehicle, biosensor and tissue engineering applications. However the darker side of CNT regarding its application goes to the toxicity of CNT depends on several intrinsic and environmental factors such as surface charge and modification, length, agglomeration etc. The conversion of the pristine CNT into its soluble form renders biocompatibility and reduces toxicity for biomedical applications $(7,8)$. Toxicological reports of single walled CNT(SWCNT) and multiwalled CNT(MWCNT) suggested lower toxicity of the later, thus making it a more attractive material for biomedical application.

Till date there has been no attempt in putting together CNT, HAP with MMT clay in a single 
composite system. In our work, CNT functionalized by acid oxidation served as template for nucleation of hydroxyapatite. The CNT-HAP thus formed was further reinforced with exfoliated MMT clay to further increase the mechanical property of the material. The synthesized composite viz CNT-HAP (HC) and CNT(HAP)-MMT(CHC) were characterized by fourier transform infrared spectroscopy(FTIR), X-ray diffraction(XRD), Scanning electron microscopy and transmission electron microscopy(TEM).

To evaluate the biomedical application of CHC, blood compatibility was studied in terms of hemolysis assay and platelet adhesion assay. In vitro dissolution assay was further studied for exploring its use as potential bone tissue engineering application.

\section{Results and Discussion}

\subsection{XRD analysis}

The $X$ ray diffraction pattern of $\operatorname{HAP}(f$-MWCNT $)$ and MMT$\mathrm{CNT}(\mathrm{HAP})$ abbreviated as $\mathrm{HC}$ as $\mathrm{CHC}$ respectively is shown in the figure $1(a, b)$. The diffraction peaks of $\mathrm{HC}$ represent the prominent reflections of hydroxyapatite. The peak at $25.86^{0}$ represents the hexagonal graphite plane was consistent with the HAP plane(9). The diffraction pattern of $\mathrm{CHC}$ shows the peak at $7.11^{0}$ representing 001 plane of MMT clay. The peak of the HAP and CNT in the diffraction pattern is subdued due to large intensity of the diffraction 001 plane of clay.

\section{FESEM}

The scanning electron micrographs shows the entangled reticulation of MWCNT with HAP clusters for $\mathrm{HC}($ Figure 3a). The FESEM image of $\mathrm{CHC}$ shows the distribution of the HAP and reticulated CNT in clay particles (Figure 3b). The TEM images show all three components ie MMT clay, HAP and MWCNT distributed in the matrix(Figure 3c).
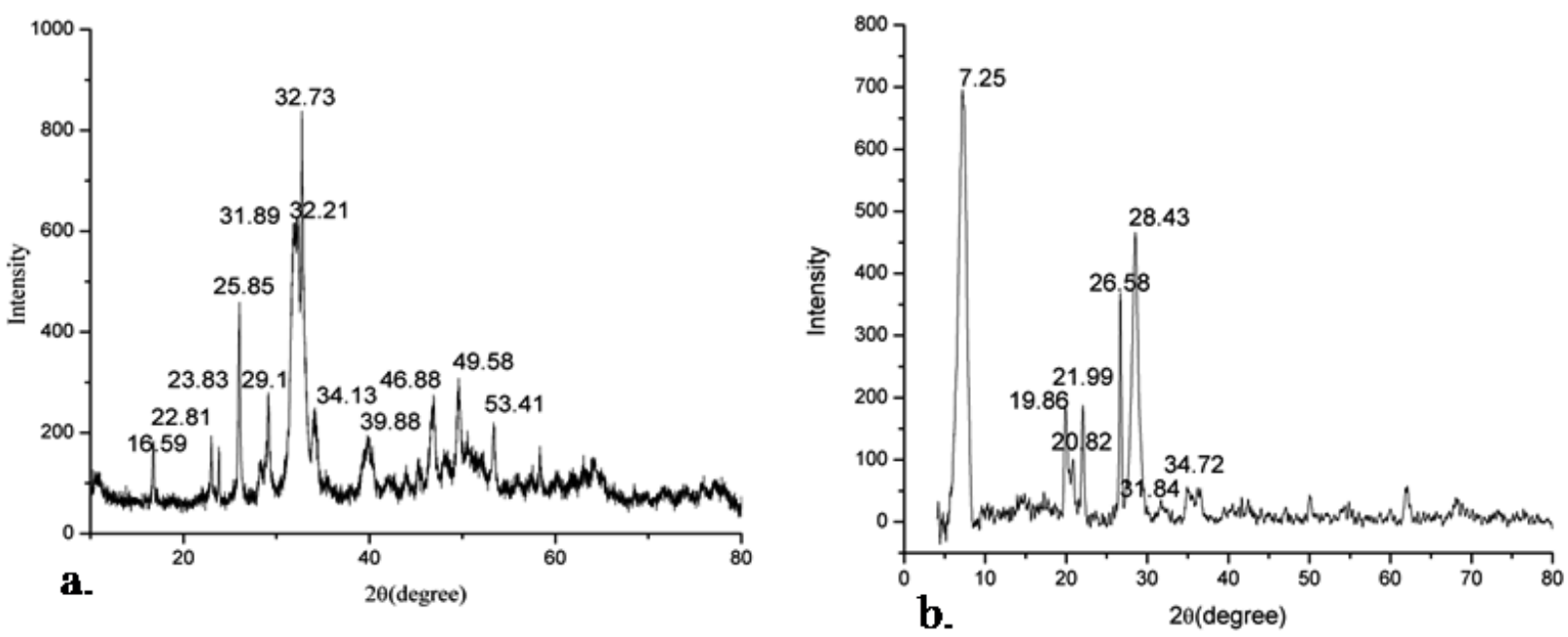

Figure 1: XRD of (a) $\mathrm{HC}$ and (b)CHC 


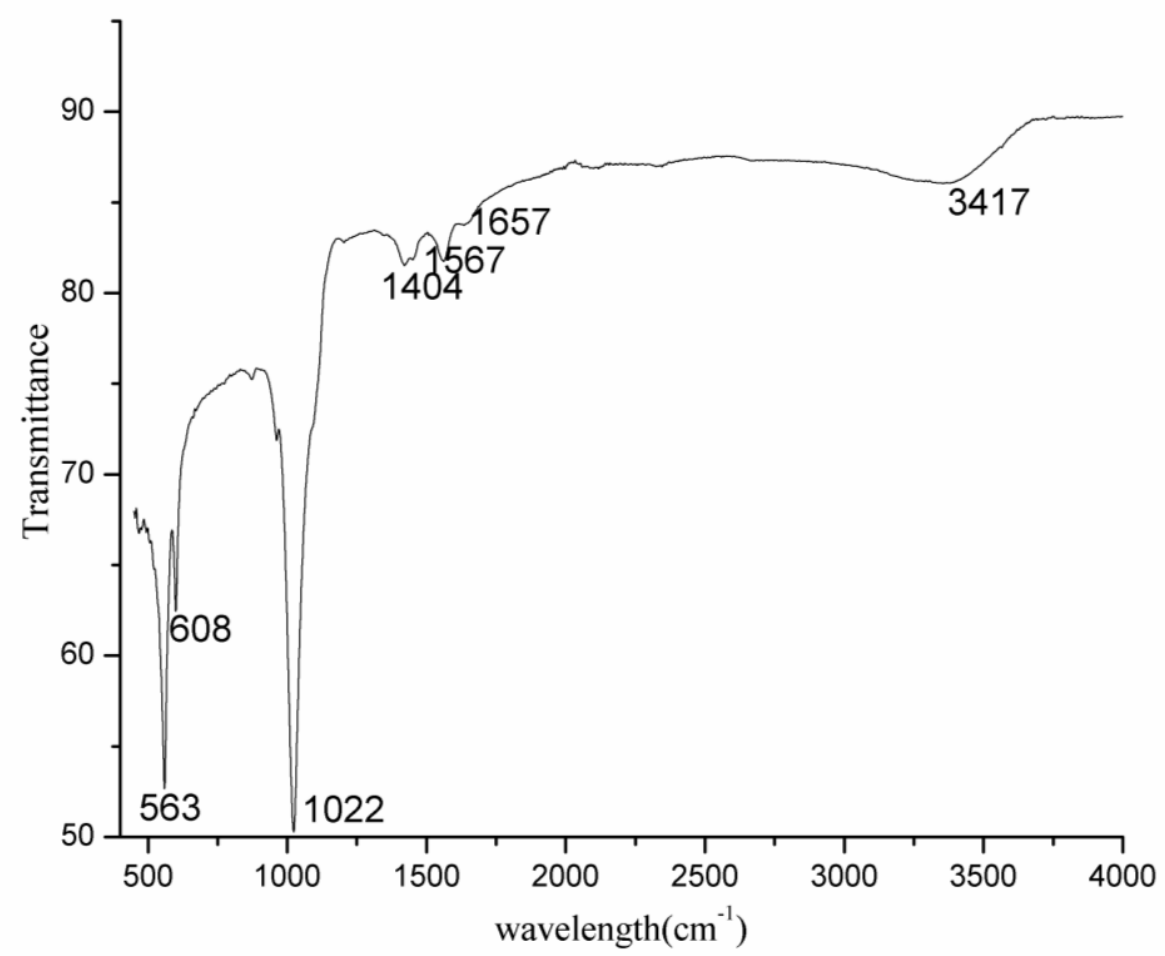

Figure 2: FTIR of HC.

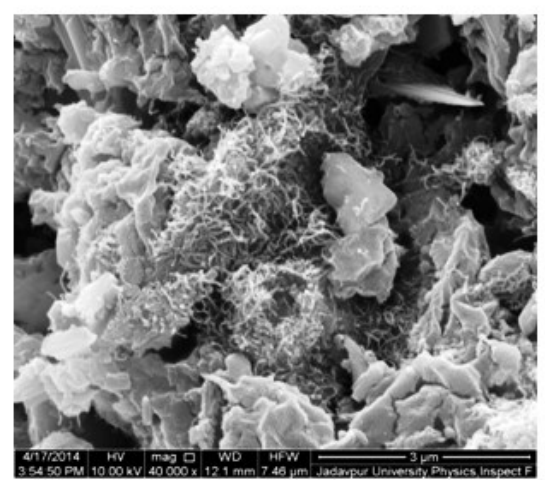

a.

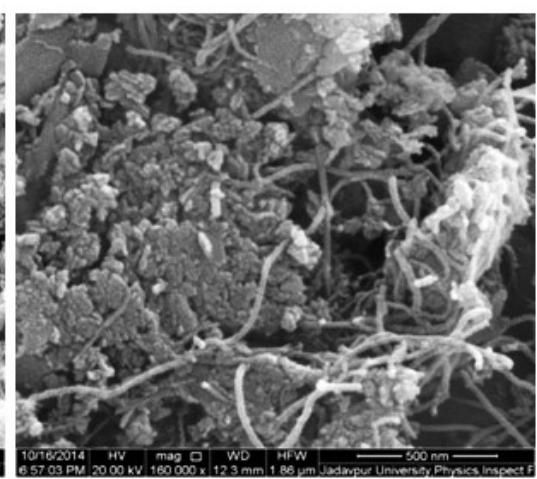

b.

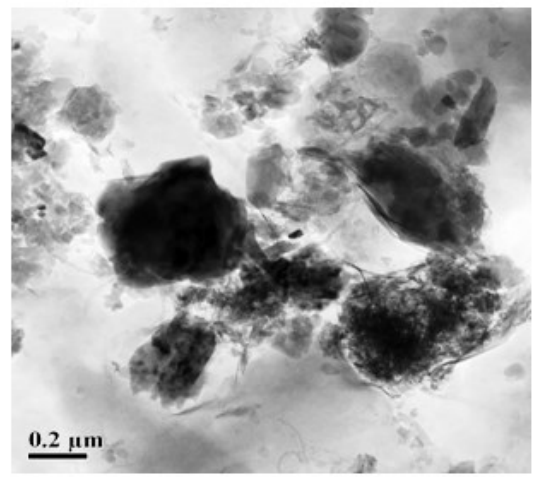

c.

Figure 3: FESEM of (a) HC and (b) CHC. HRTEM of CHC nanocomposite(c)

Table 1. Percentage release of hemoglobin from red blood cells after 60 min incubation with different concentrations of $\mathrm{CHC}$ at $37^{\circ} \mathrm{C}$.

\begin{tabular}{llllllllll}
\hline $\mathrm{CHC}(\mathrm{mg} / \mathrm{ml})$ & .1 & .5 & 1 & 3 & 6 & 8 & 10 & 15 & 20
\end{tabular}

\begin{tabular}{llllllllll}
\hline \% Hemolysis & .92 & 1.76 & 4.37 & 4.43 & 4.51 & 4.58 & 4.72 & 5 & 9.16 \\
\hline
\end{tabular}




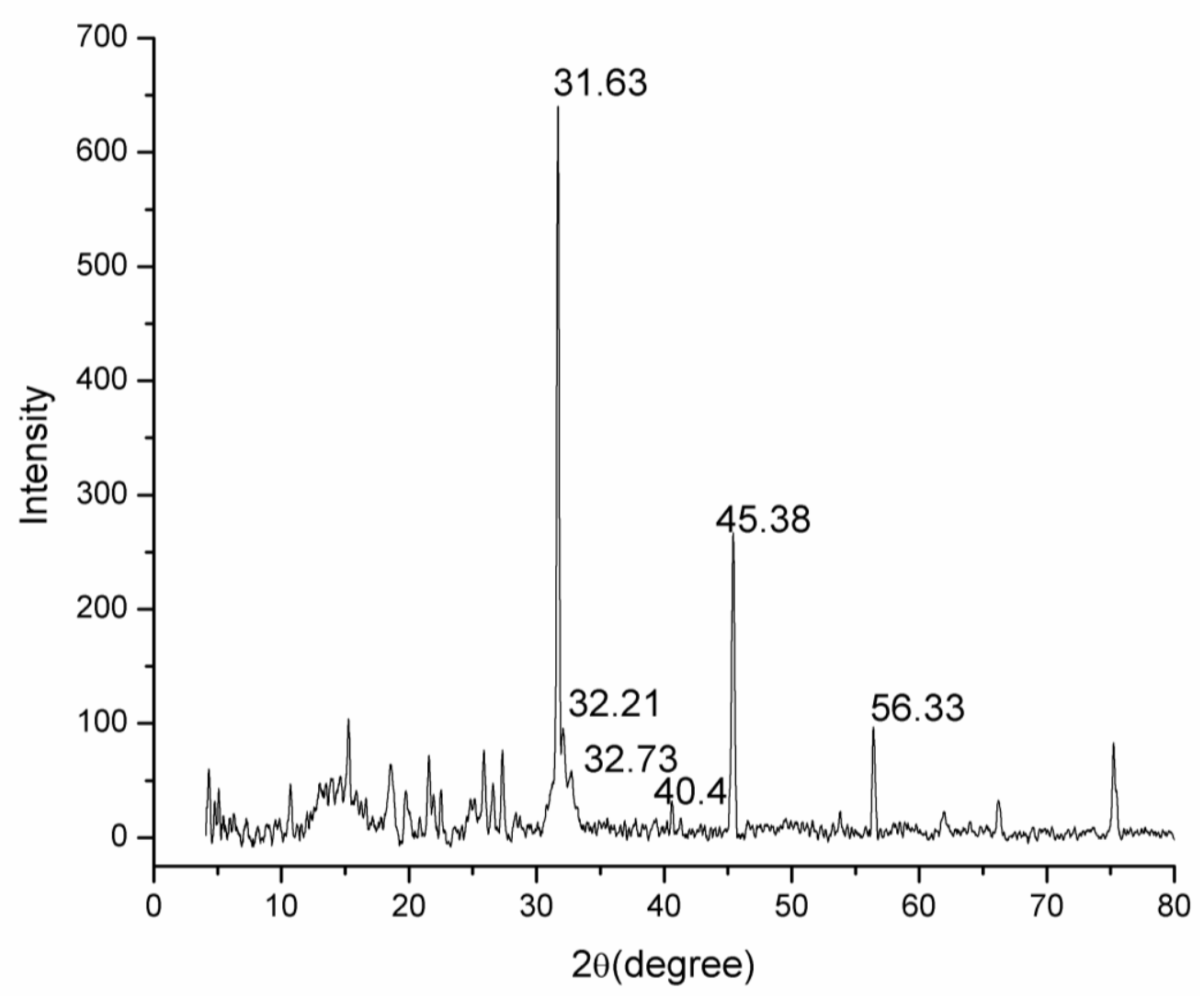

Figure: XRD Pattern of CHC nanocomposite after 30 days of immersion in SBF.

\section{2 .}
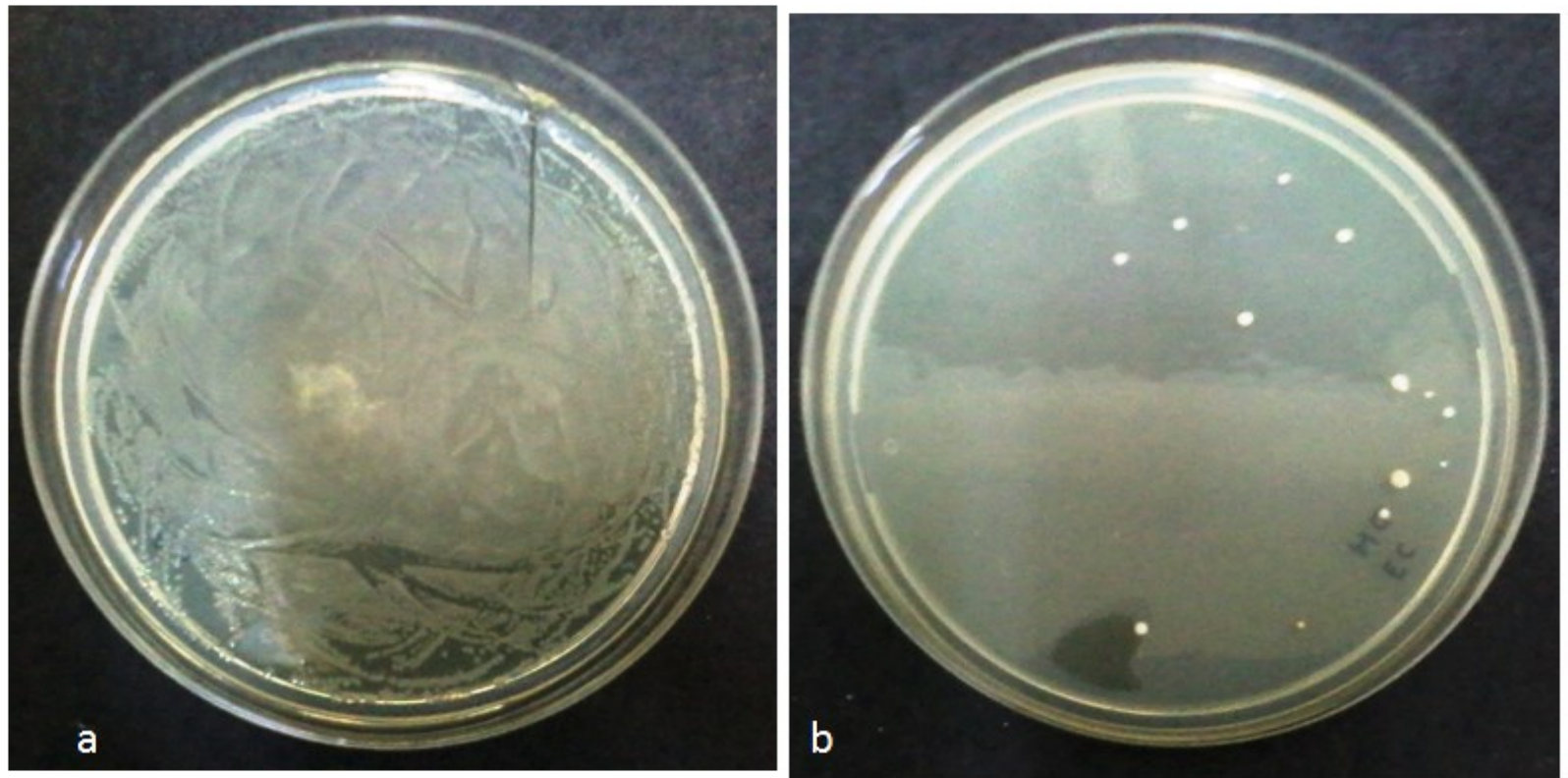

Figure 5: Nutrient Agar plates of E.coli after $24 \mathrm{~h}$ (a)control (b)CHC treated. 


\subsection{FTIR}

The FTIR pattern of the HC is represented in Figure 2. The FTIR spectrum of the MWCNTHAP sample is shown in Fig. 1.The characteristic absorption peaks of the phosphate groups for HAP are observed at $565 \mathrm{~cm}^{-1}, 611 \mathrm{~cm}^{-1}$ and $1033 \mathrm{~cm}^{-1}$, which are attributed to the $\mathrm{P}-\mathrm{O}$ bond of $\mathrm{PO} 4^{3-}$ stretching vibration and the corresponding deformation vibration(9). Small peak appearing at $1400 \mathrm{~cm}^{-1}$ is possibly associated with $\mathrm{O}-\mathrm{H}$ bending deformation in carboxylic acid groups (10). The peak at 1565 $\mathrm{cm}^{-1}$ is related to the carboxylate anion stretch mode(11). The peak at $3280-3675 \mathrm{~cm}^{-1}$ and $1640-1660 \mathrm{~cm}^{-1}$ represent stretch and bend the as-received tubes result from $\mathrm{O}-\mathrm{H}$ which are assigned to $-\mathrm{O}-\mathrm{H}$ groups of adsorbed water or covalently bonded functional groups(12).

\section{Determination of Hemolytic activity}

The hemolytic activity of the CHC composite in different concentration range is shown in table 1. The nanocomposite shows hemocompatible within $15 \mathrm{mg} / \mathrm{ml}$ concentration range showing hemolysis less than 5\%(13). Carbon naotube and montmoriollite clay composites have previously been reported as hemocompatible $(14,15)$

The platelet adhesion assay was performed using three concentration of $\mathrm{CHC}$, i.e $3,6,15 \mathrm{mg} / \mathrm{ml}$. The value of the platelet adhesion percentage was 12.03, 15.04 and $26.3 \%$ respectively, indicating the $\mathrm{CHC}$ nanocomposites were nonthombogenic within the concentration range.

\subsection{Phase analysis}

XRD patterns of the $\mathrm{CHC}$ nanocomposite after soaking in SBF is shown in figure 4. The crystallinity of HA is observed to increase significantly after 4 weeks of incubation(16). The result indicates the formation of apatite on the nanocomposite surface suggesting the bioactivity of the synthesized biomaterials(17).

\section{Antibacterial activity}

The nanocomposites show an excellent antibacterial activity against E. coli DH5 $\alpha$ (MTCC 1652). The antibacterial nature of the material was mainly due to the presence of MWCNT and MMT clay. The mechanism of antibacterial activity of CNT is associated with their diameter-dependent piercing and lengthdependent wrapping on the lysis of microbial walls and membranes, inducing release of intracellular components DNA and RNA and allowing a loss of bacterial membrane potential, demonstrating complete destruction of bacteria(18). The presence of MMT clay further escalates the antibacterial effect of the MWCNT by means of direct interaction of clay with MWCNT leading to antibacterial action by contact inhibition(19).

\section{Experimental}

\subsection{Materials}

Montmorillonite clay (MMT) $\left(\mathrm{Na}^{+}\right.$exchanged) (Nanocor Inc., USA), MWCNTs Arry International Germany, The purity of MWCNT was $60 \%$ and its diameter was $30 \mathrm{~nm}$, Calcium chloride $\left(\mathrm{CaCl}_{2}\right)$, Phosphoric acid $\left(\mathrm{H}_{3} \mathrm{PO}_{4}\right)$, 
Sodium chloride $(\mathrm{NaCl})$, bicarbonate $\left(\mathrm{NaHCO}_{3}\right)$, Potassium chloride (KCl), Dipotassium hydrogen phosphate trihydrate $\left(\mathrm{K}_{2} \mathrm{HPO}_{4} .3 \mathrm{H}_{2} \mathrm{O}\right)$, Magnesium chloride $\left(\mathrm{MgCl}_{2} .6 \mathrm{H}_{2} \mathrm{O}\right)$, Hydrochloric acid, Nitric acid (69\%), sulphuric acid (98\%) Sodium sulphate $\left(\mathrm{Na}_{2} \mathrm{SO}_{4}\right)$, Tris, Sodium citrate dehydrate, citric acid anhydrous, D- glucose from merck, India.

\subsection{Formation of MMT-CNT(HAP)}

3.2.1. Functionalization of carbon nanotubes with carboxylic groups

Functionalization of MWCNT by oxidation was done according to the method followed by Yi et al, 2006 with brief modifications. Briefly $100 \mathrm{mg}$ of MWCNT was refluxed for $10 \mathrm{~h}$ in a mixture acid solution of Sulphuric acid and Nitric acid $(3: 1 \mathrm{v} / \mathrm{v})$. The system was allowed to cool down to room temperature and sonicated in a bath sonicator for $3 \mathrm{~h}$. The dispersion was washed several times with ethanol and water until $\mathrm{PH} \sim 7$ is reached. Finally f-MWCNT was dried in oven at $70^{\circ} \mathrm{C}$.

\subsubsection{Synthesis of HAP $(f-M W C N T)$}

CNT sol was prepared by dispersing a small amount of prepared MWCNT in deionised water followed by sonication for $2 \mathrm{~h}$. To the sol, $0.5 \mathrm{M}$ of calcium chloride and phosphoric acid were separately added very slowly maintaining the $\mathrm{Ca} / \mathrm{p}$ ratio to 1.67 . The mixture was stirred for 1h. The $\mathrm{pH}$ of the system was maintained to $\sim 9$ by $1 \mathrm{~N}$ sodium hydroxide. After ageing for $24 \mathrm{~h}$ the product was dried in oven at $80^{\circ} \mathrm{C}(20)$.

3.2.3. Formation of MMT clay-HAP(f-MWCNT) Na-MMT clay were dispersed and stirred overnight in deionised water for allowing the clay layers to swell. To the dispersion $\operatorname{HAP}(f-$ MWCNT) was added and allowed to mix in a magnetic stirrer followed by sonication in bath sonicator. The composite were then oven dried and finally crushed to fine powder for characterization and further studies.

\subsubsection{X-ray diffraction (XRD)}

X-ray diffraction (XRD) Powder X-ray diffraction (XRD) patterns were recorded using a Bruker AXS (Model D8, WI, USA) setup with $\mathrm{CuK} \alpha$ radiation $(1.5409 \AA)$ and scan speed of 5 $\mathrm{min}^{-1}$ and scanning range from $5^{0}$ to $80^{0}(2 \theta)$.

3.2.5. Fourier transform infrared spectroscopy (FTIR)

Fourier transform infrared spectroscopy was performed by FTIR- 8400S model Shimadzu, Tokyo. Samples were prepared by $\mathrm{KBr}$ disk method, in which $0.2 \mathrm{~g}$ of $\mathrm{KBr}$ (spectroscopy grade) was thoroughly mixed with sintered sample powder ( $1 \%$ by weight of $\mathrm{KBr}$ ) and then made into disks by uniaxial pressing. Scanning range was set from 400 to $2000 \mathrm{~cm}^{-1}$ under Happ-Genzel configuration.

\subsubsection{Electron microscopic study}

Morphological characteristics of the samples were observed by scanning electron microscope (SEM) model FEI Quanta 250 (USA). A minute quantity of the sample was directly place on carbon coated grid, sputter coated with gold and then observed SEM.

\subsubsection{Transmission electron microscopy}

The particle size of synthesized nanocomposites was observed by JEM- 2100 HRTEM model. A minute quantity of the sample was dispersed in water by sonication and observed under the microscope.

\subsubsection{Hemocompatibility}

Platelet adhesion analysis

The assay was done according to the method followed by (21)Sun et al, 2014. Whole mice blood (citrated) was centrifuged at $1500 \mathrm{rpm}$ for $15 \mathrm{~min}$ to obtain platelet-rich plasma (PRP) supernatant. Samples were equilibrated with normal saline at $37^{\circ} \mathrm{C}$ for $2 \mathrm{~h}$. 1 or $1.5 \mathrm{~mL}$ fresh PRP at a density of $5 \times 10^{5}$ cells/mL (N1) was 
added in a $2-\mathrm{mL}$ tube), incubated at $37^{\circ} \mathrm{C}$ for $3 \mathrm{~h}$, then removed. The numbers of platelets in PRP not adhered to the specimens were recorded using a cell counter (N2). The platelet adhesion ratio was calculated using the following equation:

$$
\frac{N 1-N 2}{N 1} \times 100
$$

Platelet adhesion (\%) $=$

\section{Hemolysis analysis}

Test specimens in $2 \mathrm{~mL}$ centrifuge tubes were equilibrated in saline $(0.9 \%(\mathrm{w} / \mathrm{v}) \mathrm{NaCl})$ at $37^{\circ} \mathrm{C}$ for $30 \mathrm{~min}$. Whole blood from healthy mice was collected into sterile sodium citrate buffer, and diluted $(0.2 \mathrm{~mL}$ in $10 \mathrm{~mL}$ saline).Equal amount of the diluted blood was added to the test specimen. Distilled water and physiological saline were used as negative control $(\mathrm{N})$ and positive control $(\mathrm{P})$, respectively. Samples were placed in a static incubator at $37^{\circ} \mathrm{C}$ for a further 60 min. After hemolysis, samples were centrifuged at $2500 \mathrm{rpm}$ for $5 \mathrm{~min}(21)$ (Sun et al, 2014). The absorbance of the supernatant was measured at $545 \mathrm{~nm}$. The hemolysis percentage was calculated according to the following equation:

Hemolysis $(\%)=\frac{A 2-A 1}{A 3-A 1} \times 100$

where $\mathrm{A} 1, \mathrm{~A} 2$, and $\mathrm{A} 3$ are the absorbance of the negative control, sample, and positive control, respectively.

\subsubsection{Biomineralization}

The test samples bioceramic was immersed into a 1.5-times concentrated simulated body fluid (SBF) at $37^{\circ} \mathrm{C}$ up to 7 days, and the SBF solution was change every $24 \mathrm{~h}$. The material was removed from the SBF solution after 7 day incubation, gently rinsed with water, and air dried at room temperature. The phases present in the coating were determined by XRD analysis $(16,22)$.

\subsubsection{Antibacterial activity}

The antibacterial activity of the synthesized nanocomposites was performed against E.coli cells. Briefly overnight grown bacterial cell in nutrient broth representing $10^{7} \mathrm{CFU} / \mathrm{ml}$ was washed thrice with PBS 7.4 at 5000rpm for 10 mins. This was followed by incubating $10^{5}$ cells in a fresh nutrient broth with $10 \mathrm{mg}$ of $\mathrm{CHC}$ and $\mathrm{HC}$ and incubated at $37^{\circ} \mathrm{C}$. Untreated control served as control. After overnight incubation the culture was plated in nutrient agar plate $(1.8 \%)$ and further incubated overnight.

\section{Conclusion}

In summary, the synthesized nanocomposite MMT clay, HAP and oxidized MWCNT show a good hemocompatibility, showing minimum hemolysis and platelet adhesion which increases in a concentration dependent manner. Further the material was found to be bioactive, showing apatite formation after immersion in stimulating biological fluid(SBF) after 30 days of immersion. The material exhibited an excellent antibacterial activity. Thus the synthesized nanocomposite may act as a good candidate as an antibacterial biomaterial for biomedical application.

Acknowlwdgement

We are grateful to the Department of Science and Technology, Govt. of India for financial assistance.

Conflicts of Interest

The authors declare no conflict of interest. 


\section{References and Notes}

1. Murray, H. H. (2000). Traditional and new applications for kaolin, smectite, and palygorskite: a general overview. Applied clay science, 17(5), 207-221.Jonathan I. Dawson and Richard O. C. Oreffo, Adv. Mater. 2013, 25, 4069-4086.

2. Dawson, J. I., \& Oreffo, R. O. (2013). Clay: new opportunities for tissue regeneration and biomaterial design. Advanced Materials, 25(30), 4069-4086.

3. Katti, K. S., Katti, D. R., \& Dash, R. (2008). Synthesis and characterization of a novel chitosan/montmorillonite/hydroxyapatite nanocomposite for bone tissue engineering. Biomedical Materials, 3(3), 034122.

4. Mieszawska, A. J., Fourligas, N., Georgakoudi, I., Ouhib, N. M., Belton, D. J., Perry, C. C., \& Kaplan, D. L. (2010). Osteoinductive silk-silica composite biomaterials for bone regeneration. Biomaterials, 31(34), 8902-8910.

5. Liu, D. M., Troczynski, T., \& Tseng, W. J. (2001). Water-based sol-gel synthesis of hydroxyapatite: process development. Biomaterials, 22(13), 1721-1730.

6. Hirata, E., Uo, M., Takita, H., Akasaka, T., Watari, F., \& Yokoyama, A. (2011). Multiwalled carbon nanotube-coating of 3D collagen scaffolds for bone tissue engineering. Carbon, 49(10), 3284-3291.

7. Firme, C. P., \& Bandaru, P. R. (2010). Toxicity issues in the application of carbon nanotubes to biological systems. Nanomedicine: Nanotechnology, Biology and Medicine, 6(2), 245-256.

8. Liu, Y., Zhao, Y., Sun, B., \& Chen, C. (2012). Understanding the toxicity of carbon nanotubes. Accounts of Chemical Research, 46(3), 702-713.

9. Liu, Z., Chen, L., Zhang, Z., Li, Y., Dong, Y., \& Sun, Y. (2013). Synthesis of multi-walled carbon nanotube-hydroxyapatite composites and its application in the sorption of Co (II) from aqueous solutions. Journal of Molecular Liquids, 179, 46-53.

10. Goyanes, S., Rubiolo, G. R., Salazar, A., Jimeno, A., Corcuera, M. A., \& Mondragon, I. (2007). Carboxylation treatment of multiwalled carbon nanotubes monitored by infrared and ultraviolet spectroscopies and scanning probe microscopy. Diamond and related materials, 16(2), 412-417.

11. Abuilaiwi, F. A., Laoui, T., Al-Harthi, M., \& Atieh, M. A. (2010). Modification and functionalization of multiwalled carbon nanotube (MWCNT) via fischer esterification. Arabian Journal for Science and Engineering, 35(1C), 37-48.

12. Osswald, S., Havel, M., \& Gogotsi, Y. (2007). Monitoring oxidation of multiwalled carbon nanotubes by Raman spectroscopy. Journal of Raman Spectroscopy, 38(6), 728-736.

13. Wang C, Wang S, Li K, Ju Y, Li J, et al. (2014) Preparation of Laponite Bioceramics for Potential Bone Tissue Engineering Applications. PLoS ONE 9(6):e99585.

14. Zhou, N., Fang, S., Xu, D., Zhang, J., Mo, H., \& Shen, J. (2009). Montmorillonite-phosphatidyl choline/PDMS films: a novel antithrombogenic material. Applied Clay Science, 46(4), 401-403.

15. Murugesan, S., Park, T. J., Yang, H., Mousa, S., \& Linhardt, R. J. (2006). Blood compatible carbon nanotubes-nano-based neoproteoglycans. Langmuir,22(8), 3461-3463. 
16. Gu, Y. W., Khor, K. A., \& Cheang, P. (2003). In vitro studies of plasma-sprayed hydroxyapatite/Ti-6Al-4V composite coatings in simulated body fluid (SBF). Biomaterials, 24(9), 1603-1611.

17. Zadpoor, A. A. (2014). Relationship between in vitro apatite-forming ability measured using simulated body fluid and in vivo bioactivity of biomaterials.Materials Science and Engineering: C, 35, 134-143.

18. Chen, H., Wang, B., Gao, D., Guan, M., Zheng, L., Ouyang, H., ... \& Feng, W. (2013). Broad-Spectrum Antibacterial Activity of Carbon Nanotubes to Human Gut Bacteria. Small, 9(16), 2735-2746.

19. Bagchi, B., Kar, S., Dey, S. K., Bhandary, S., Roy, D., Mukhopadhyay, T. K., ... \& Nandy, P. (2013). In situ synthesis and antibacterial activity of copper nanoparticle loaded natural montmorillonite clay based on contact inhibition and ion release. Colloids and Surfaces B: Biointerfaces.

20. Liao, S., Xu, G., Wang, W., Watari, F., Cui, F., Ramakrishna, S., \& Chan, C. K. (2007). Selfassembly of nano-hydroxyapatite on multi-walled carbon nanotubes. Acta Biomaterialia, 3(5), 669-675.

21. Sun, D., Hao, Y., Yang, G., \& Wang, J. (2015). Hemocompatibility and cytocompatibility of the hirudin-modified silk fibroin. Journal of Biomedical Materials Research Part B: Applied Biomaterials, 103(3), 556-562.

22. Wang, X., Zhou, N., Yuan, J., Wang, W., Tang, Y., Lu, C., ... \& Shen, J. (2012). Antibacterial and anticoagulation properties of carboxylated graphene oxide-lanthanum complexes. Journal of Materials Chemistry, 22(4), 1673-1678.

(C) 2015 by the authors; licensee MDPI, Basel, Switzerland. This article is an open access article distributed under the terms and conditions defined by MDPI AG, the publisher of the Sciforum.net platform. Sciforum papers authors the copyright to their scholarly works. Hence, by submitting a paper to this conference, you retain the copyright, but you grant MDPI AG the non-exclusive and unrevocable license right to publish this paper online on the Sciforum.net platform. This means you can easily submit your paper to any scientific journal at a later stage and transfer the copyright to its publisher (if required by that publisher). (http://sciforum.net/about ). 